\title{
A POPULAÇÃO LGBTI+ BRASILEIRA E A PANDEMIA DE COVID-19: ALGUNS APONTAMENTOS SOBRE ISOLAMENTO SOCIAL, SAÚDE E DIREITOS HUMANOS
}

\author{
THE LGBTI+ BRAZILIAN POPULATION AND THE COVID-19 \\ PANDEMIC: NOTES ON SOCIAL ISOLATION, HEALTH, \\ AND HUMAN RIGHTS
}

\author{
Ana Karina Silva Azevedo ${ }^{1}$ \\ Maria Vanessa Morais da Silva ${ }^{2}$
}

\begin{abstract}
RESUMO
A proposta deste ensaio é sinalizar, refletir e problematizar as dificuldades da população LGBTI+ - Gays, Lésbicas, Bissexuais, travestis, transsexuais, intersexo e mais - vivenciadas na pandemia de COVID-19 a respeito dos impactos do isolamento social, as questões de saúde e direitos humanos. A população LGBTI+ ainda é significativamente invisibilizada na sociedade brasileira, bem como na mídia e cultura. E, apesar de ser uma temática recente, o isolamento social e os desdobramentos da pandemia lançaram luz sobre o cotidiano dessas invisibilidades. Foi possível perceber que o entrelaçamento entre a pandemia e a população LGBTI+ proporcionou uma maior vulnerabilidade, tanto no aspecto singular, social, econômico, como político. Pessoas LGBTI+ sofrem ainda mais violências, passam fome, perdem direitos e ficam às margens de uma existência digna.
\end{abstract}

Palavras-chave: Pandemia de COVID-19; LGBTI+; Vulnerabilidades.

\begin{abstract}
The purpose of this essay is to signal, problematize, and reflect on the difficulties of the LGBTI+ population Gays, Lesbians, Bisexuals, transvestites, transsexuals, intersex, and more - experienced in the COVID-19 pandemic regarding the impacts of social isolation, health issues, and human rights. The LGBTI+ population is still significantly invisible in Brazilian society and the media and culture. And, despite being a recent theme, social isolation and the consequences of the pandemic shed light on the daily lives of these invisibilities. It was possible to notice that the intertwining between the pandemic and the LGBTI+ population provided greater vulnerability, both in the singular, social, economic, and political aspects. LGBTI+ people suffer even more violence, go hungry, lose their rights, and are on the margins of a dignified existence.
\end{abstract}

Keywords: COVID-19 pandemic; LGBTI+; vulnerabilities.

\footnotetext{
${ }^{1}$ Atualmente é professora do Departamento de Psicologia da Universidade Federal do Rio Grande do Norte e professora colaboradora do Programa de Pós-graduação em Psicologia da UFRN. Doutora e Mestra em Psicologia pela Universidade Federal do Rio Grande do Norte (UFRN). e-mail: kakaiaazevedo@gmail.com

${ }^{2}$ Atualmente é Mestranda pelo Programa de Pós-Graduação em Psicologia - (PPgPsi - UFRN). Psicóloga pela Universidade Federal do Rio Grande do Norte - UFRN (2019). e-mail: vanessamorais21@gmail.com
} 


\section{Debates Insubmissos}

Revista

\section{INTRODUÇÃO}

Segundo a Organização Mundial da Saúde - OMS (2020) em 11 de março de 2020, a COVID-19 foi caracterizada como uma pandemia, termo que se refere à amplitude da sua distribuição geográfica. Desde então, medidas de isolamento, distanciamento social e, em alguns países, lockdown foram aplicadas como medida de contenção da propagação do vírus. Muitas localidades do mundo, incluindo o Brasil, entraram em quarentena, trazendo à população mudanças sociais, impactos econômicos, tensionamentos políticos e problemáticas emocionais.

Os impactos psicológicos em meio a uma situação de crise sanitária mundial, como a que recentemente fomos acometidos com a pandemia de COVID-19, podem ser diversos. Segundo pesquisadores da Fundação Oswaldo Cruz (FIOCRUZ, 2020), durante uma pandemia espera-se que as pessoas fiquem constantemente em estado de alerta, angustiados, confusos e com medo. É esperado também a sensação recorrente de ansiedade, raiva, tristeza e impotência perante os acontecimentos. Estima-se também, que cerca da metade da população exposta a uma epidemia pode vir a sofrer alguma manifestação psicopatológica, caso não seja feita nenhuma intervenção de cuidado específico para as reações e sintomas manifestados.

Em estudo relacionando os impactos do isolamento social durante a pandemia de COVID-19 à saúde mental da população em geral, pesquisadores da Universidade Nacional da Colômbia sinalizam impactos sem precedentes e muitos desafios para a saúde mental. De acordo com os pesquisadores, nesse cenário, durante uma pandemia, o medo intensifica os níveis de estresse e ansiedade em pessoas saudáveis e aumenta os sintomas daquelas com transtornos mentais pré-existentes (RAMÍREZ-ORTIZ; CASTRO-QUINTERO; LERMACÓRDOBA; YELA-CEBALLOS; ESCOBAR-CÓRDOBA, 2020).

De acordo com Brooks, Webster, Smith, Woodland, Wessely, Greenberg e Rubin (2020) a vivência de emoções extremas, como sentimentos de incômodo, raiva, tristeza, angústia, frustração, indignação, preocupação, receio, sem autorregulação, que provocam medo, insegurança e risco de vida, principalmente em pessoas em isolamento social, pode 


\section{Revista \\ Debates Insubmissos}

evoluir para transtornos de ansiedade, Transtorno de Estresse Pós-Traumático (TEPT), sintomas psicóticos, depressão e suicídio.

Ainda sobre o impacto emocional em uma pandemia, Deyoung, Eastburg, Edwards, Halstead, Mancuso, Rollings e Vandentoorn (2020) em estudo publicado pela Pine Rest Christian Mental Health Services, predizem que na cidade de Michigan, em decorrência da atual pandemia, pode-se ter um aumento de $32 \%$ nas taxas de suicídio caso nada seja feito para enfrentar essa realidade. Este estudo aponta ainda como grupos de risco: profissionais de saúde, cuidadores, crianças, adolescentes, idosos, pessoas com doenças mentais pré-existentes, comunidade LGBTI+ - Lésbicas, Gays, Bissexuais, Travestis, Transsexuais, Intersexo e mais - e pessoas com transtorno do espectro autista.

É importante lembrar que mesmo em uma situação de crise global, como a de uma pandemia, cujo contexto propicia impactos psicológicos para todas as pessoas de maneira geral, há algumas populações e comunidades que apresentam maior vulnerabilidade bio-sóciopolítico-econômica, em especial no Brasil, um país culturalmente tão diverso e economicamente tão desigual. Nessa direção, pretende-se aqui destacar a população LGBTI+, que, segundo Reis (2012) tem seus direitos violados, experienciam a fragilidade e a carência de políticas públicas de saúde e assistência adequadas, e são massacradas diariamente por causa da LGBTIfobia. É uma população que habita uma sociedade e uma cultura as quais manejam o entendimento das questões de gênero e sexualidade por via de um viés moral, separatista e preconceituoso.

As vulnerabilidades singulares, sociais, econômicas e políticas da população LGBTI+ são históricas. Segundo o site Politize (2020) o conceito de vulnerabilidade é multifatorial e está relacionado, sobretudo, à exclusão de cidadãos e a falta de representatividade. Para Facchini (2009) a noção de vulnerabilidade pode ser tomada de maneira imprescindível e inerente a dados grupos populacionais, como por exemplo: LGBTI+ pobres, adolescentes ou negros(as), numa articulação coletiva muito mais que a níveis individuais. Tal autora destaca que é preciso pensar que refletir sobre a vulnerabilidade nesta população é também discutir sobre as condições ontológicas de existência em um mundo marcado por preconceitos e 
opressões, desta forma, pensando não só no sujeito vulnerabilizado, mas também nos contextos que os vulnerabilizam.

Sobre isso Facchini (2009, p. 153) vai dizer

\begin{abstract}
Isso passa por não limitar os eixos explicativos da vulnerabilidade a gênero e/ou sexualidade, nem separá-los radicalmente entre orientação sexual e identidade de gênero, tomadas como especificamente relacionadas a gays, lésbicas e bissexuais de um lado e travestis, transexuais e transgêneros de outro. Passa também por desfocar políticas de sujeitos e opressões específicas para contextos que vulnerabilizam.
\end{abstract}

Ainda sobre reflexões acerca da vulnerabilidade nesta população, Cabral (2016), destaca que pessoas LGBT's foram vítimas de trabalhos forçados, experiências científicas, castigos físicos, prisão, lobotomia, castração química, fogueira, morte por decapitação e várias outras atrocidades (in)contáveis, (im)pensáveis. Segundo esta autora, durante a ditadura militar no Brasil pessoas LGBT's foram perseguidas, presas, censuradas e perderam seus empregos em prol da moral e bons costumes ditados pelo Estado. Os autores Mendes e Silva (2020) nos lembram que se trata de pessoas que têm suas existências patologizadas e incompreendidas, de uma população invisibilizada, perseguida, criminalizada e assassinada, sobretudo quando se fala sobre assassinato, vivemos em um país como o Brasil, onde mais se mata LGBT's no mundo.

É importante destacar que o atual contexto político e social brasileiro trouxe ainda mais vulnerabilidades à população LGBTI+. Em decretos da Presidência da República (BRASIL, 2019), mesmo antes da pandemia de COVID-19, o Ministério dos Direitos Humanos foi extinto. O então encarregado da promoção de políticas para inclusão de grupos minoritários passa a ser chamado de Ministério da Mulher, Família e Direitos Humanos, e retira a comunidade LGBTI+ da carta de diretrizes de direitos humanos, por meio da medida provisória $n^{\circ} 870 / 19$. Isto implica um cenário de perda de direitos, que invisibilizam, ainda mais, esta população.

Desta forma, cabe-se interrogar sobre como a vivência de um isolamento/distanciamento social na pandemia de COVID-19 podem acentuar questões já vivenciadas, mesmo antes da pandemia, por algumas pessoas LGBTI+ como: solidão, isolamento, fragilidade dos direitos humanos, desmonte de políticas públicas de saúde e assistência, além de um cardápio de violências. 
Partindo destas reflexões, algumas questões são inquietantes: Como é estar confinado em locais e cenários de não aceitação de quem se é, como muitas vezes é o ambiente familiar? Questões assim se fundam em estudos, como o do coletivo \#VoteLGBT (2020), que apontam que 1/3 das violências contra pessoas LGBTI+ acontecem no ambiente familiar. Em outra direção: Como tem se apresentado para a população LGBTI+ a privação do uso dos espaços públicos? Os quais, antes da pandemia, poderiam representar uma forma mais livre de expressar seu gênero e sua sexualidade.

Essas duas questões colocadas anteriormente são problematizadas a partir dos desafios que podem estar presentes nas condições de isolamento/distanciamento social vivenciados pela população LGBTI+ e que servem como motivadores para as discussões do presente ensaio. Tais problematizações já desvelam o quanto para essa população a questão de um pertencimento a um habitar físico e afetivo ganham importância e, já poderiam ser uma questão mesmo antes da pandemia. A partir delas podemos pensar inúmeras condições de existência dessa população entre o público e o privado, entre o familiar e o estranhamento. Nessa direção, o presente ensaio objetiva sinalizar, refletir e problematizar as dificuldades e impactos do isolamento social, e as questões de saúde e direitos humanos da população LGBTI+, na pandemia de COVID-19.

\section{ISOLAMENTO SOCIAL, SAÚDE E DIREITOS HUMANOS. O QUE DIZ RESPEITO À POPULAÇÃO LGBTI+?}

Embora, algumas vezes, se fale de isolamento social, saúde e direitos humanos como temas discutidos separadamente, no presente tópico deste manuscrito, para tecer um olhar sobre a população LGBTI+, entendemos que a complexidade do ser humano e de sua diversidade nos direciona a uma não fragmentação, sempre num movimento de interação, no qual ao se falar sobre o isolamento social nesta população, fala-se inerentemente sobre saúde e direitos humanos. O que é falar sobre esses aspectos para a população LGBTI+ em meio a uma pandemia? 


\section{Revista \\ Debates Insubmissos}

A pandemia mostra e ratifica para o mundo a grande desigualdade social que é instaurada no Brasil, além das informações desencontradas e omissão do Estado. Em meio a pandemia e anos de precarização de serviços públicos e políticas sociais, desponta o desamparo econômico e social da população brasileira. E algumas comunidades mais vulneráveis, como a população LGBTI+, que padecem amargamente marginalizadas e sem apoio e gestão do Estado, enfrentam, em maior proporção, dificuldades relacionadas à saúde mental, afastamento da rede de apoio habitual e dificuldades financeiras (BARRETO, 2020).

É bem verdade que os direitos de saúde, assistência, emprego e moradia, bem como a construção de uma rede de apoio para a população LGBTI+ são questões sempre presentes nesta comunidade, tendo em vista a enorme luta promovida pelos movimentos sociais em busca de direito, respeito e cidadania. Mas esses direitos básicos à vida, não seriam direitos incontestáveis aos humanos? Por que, então, que a população LGBTI+ precisa lutar pelo mínimo para existir? É bem verdade que essas questões se sobressaem em momentos de crises, mas elas são também questões éticas, políticas, sociais e históricas que permeiam à comunidade LGBTI+ entre décadas.

Recorrendo à história, em 1952, a primeira versão do Manual Diagnóstico e Estatístico de Transtorno Mentais (DSM) classificou a homossexualidade como uma desordem, sendo compreendida como uma doença mental e uma inversão anormal de papéis, e nesse sentido ao ser tratada como uma patologia, impôs tratamentos extremamente desumanos, que variava entre terapias de choques convulsivos, lobotomia e terapias por aversão. A ideia da homossexualidade como uma patologia durou muito tempo. A Associação Americana de Psiquiatria retirou a orientação sexual da lista de transtornos mentais do DSM apenas em 1973. A OMS somente em 1990 na décima publicação da classificação internacional de doenças (CID-10), e desde 1991, a Anistia Internacional considera violação aos direitos humanos a proibição da homossexualidade (VECCHIATTI, 2012).

Diversos grupos que fazem parte do movimento LGBT, que é símbolo e atua como dispositivo representativo e político na articulação de lutas sociais por reconhecimento e direitos da população LGBTI+, batalharam pelo fim da discriminação e a abolição da 


\section{Revista \\ Debates Insubmissos}

classificação científica que designa a homossexualidade como doença, assim como os estigmas que marcam esses corpos e essas sexualidades que fogem do padrão da sociedade heteronormativa (FACCHINI, 2009).

Ainda, segundo Facchini (2009), as consequências da associação entre homossexualidade e doença, assim como outras associações estigmatizadoras e opressoras para com a população LGBTI+, como pecado, crime, desvio de conduta, comportamento anormal, dentre outras, são sentidas até hoje. E mesmo que atualmente se tenha excluído o caráter patológico da homossexualidade, o sofrimento vivido por essas pessoas na sociedade contemporânea ainda é bem presente, principalmente na sua relação com as várias formas de opressão, preconceito e violência.

A homossexualidade, ou melhor dizendo as orientações sexuais e identidades de gênero que destoam das sexualidades heteronormativas são um mal a ser excluído a todo custo? Se a resposta for afirmativa, então o Estado está correspondendo ao seu papel encarnado de omissão frente à comunidade LGBTI+. Todo o preconceito e estigma arraigados por décadas com essas pessoas se manifesta em diferentes esferas da sociedade, seja familiar, comunitário ou nos diversos níveis políticos e de poder. Isso tem ficado cada vez mais visível em meio à crise sanitária do COVID-19 e a gestão de um governo neoliberal e radical.

Michel Foucault (1988) ao analisar o discurso sobre a sexualidade no ocidente, reflete que constituíram a heterossexualidade como padrão de normalidade e que a ciência médica enfatiza a função reprodutiva do sexo e a concepção binária de gênero, isto é, o gênero é definido a partir das categorias macho e fêmea. A genealogia da sexualidade descrita por esse autor permite refletir também sobre a hegemonia do discurso de verdade da medicina na sociedade contemporânea no que tange a sexualidade humana.

Nessa direção, a filósofa Judith Butler (2015), assinala que existe uma estrutura de práticas reguladoras que visam manter a naturalização da linearidade entre sexo, gênero e sexualidade, considerando "normal" tão somente a ideia do que é cisgênero, ou seja, o gênero em conformidade com o sexo biológico e a heterossexualidade. A autora fala ainda sobre as correções de desvio dessa norma, que aparecem como castigos, ofensas verbais e exclusão 
social, além de violência física e homicídio, o que gera medo e sofrimento entre a população LGBTI+.

Uma grande parte da população LGBTI+ experiencia o preconceito e violência dentro das suas próprias famílias. De acordo com a pesquisa do \#VoteLGBT (2020) muita gente relatou ter sofrido alguma violência ou foi expulsa de casa nesse período de pandemia, lugar onde um terço dessa população sofre variados tipos de violências. E segundo Fundação Instituto de Pesquisas Econômicas (FIPE, 2015) em relatório entregue à Secretaria de Assistência e Desenvolvimento Social de cidade de São Paulo, mesmo antes da pandemia, entre 5,3\% e 8,9\% do total da população em situação de rua na capital, pertencem à comunidade LGBTI+.

Com medo da rejeição, agressões físicas, verbais e expulsão de casa, as pessoas LGBTI+ que sofrem preconceitos por sua orientação sexual ou identidade de gênero por parte de seus familiares, evita ser quem é neste momento que não pode ocupar outros espaços fora de casa. Por outro lado, alguns espaços públicos também são perigosos para a população LGBTI+. Segundo a pesquisa "Violência contra LGBT+ no contexto eleitoral e pós-eleitoral" do portal Gênero e Número (BULGARELLI; FONTGALAND; MARTINS; FERRARI; BIANCONI; SILVA, 2019), 83\% dos episódios de violência que ocorreram antes e após as eleições de 2018 foram nas ruas.

Apesar desse fato, a ocupação da cidade como espaço público fortalece o pensamento de que acessá-la significa um processo político, coletivo e de resistência às formas de violência e opressão. Nessa direção, como afirma Silva (2020), o contexto de isolamento social atrelado à pandemia de COVID-19 trouxe desafios e problemas para as cidades e isto reflete diretamente nas relações interpessoais, sobretudo no contexto da população LGBTI+, as quais não convivem com aceitação familiar e consequentemente a redução de sua rede de apoio, atrelada ao impulsionamento da violência doméstica.

Onde habitar? Essa pergunta fica pulsando! Se por um lado, para uma parcela dessa população o isolamento social com suas famílias tem sido motivo de sofrimento durante a pandemia de COVID-19, por outro lado alguns espaços públicos são lugares de discriminação, 


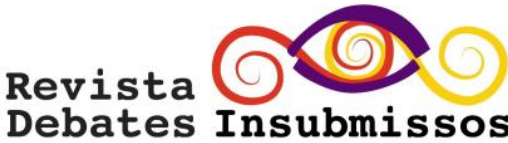

preconceito, violência e morte. A sensação de não-pertencimento e invisibilidade se presentificam na população LGBTI+.

No Brasil está sendo cada vez mais difundida por meio de um discurso político-religioso e separatista, a ideia que o movimento LGBT pretende destruir a família tradicional brasileira e os valores cristãos, tornando a comunidade LGBTI+ uma espécie de mal a ser combatido, pensamento esse advindo de um tensionamento político-partidário radical de extrema direita e polarizador. É importante lembrar, segundo Trzan-Ávila (2019), que a violência não se apresenta somente por atos públicos ou privados que podemos claramente denominar de violentos, mas também pela anulação de direitos, por falta de pautas e políticas públicas importantes para o reconhecimento da população LGBTI+.

Refletindo sobre isso, é importante dimensionar os aspectos sobre a qualidade de vida e saúde da população LGBTI+. De acordo com a Política Nacional de Saúde Integral da população LGBT do Ministério da Saúde (BRASIL, 2013) é relevante compreender que os processos de saúde-doença são determinados socialmente pela exclusão, desemprego, falta de acesso à moradia e à alimentação, bem como inexistência ou dificuldade no acesso à educação, saúde, lazer e cultura. Tais questões interferem diretamente na qualidade de vida e saúde. E, sobretudo, é imprescindível reconhecer que as formas de discriminação e violência, como no caso da LGBTIfobia, devem ser consideradas na determinação de sofrimento e de doença.

A Política Nacional de Saúde Integral da população LGBTI+, instituída pela portaria ${ }^{\circ}$ 2.836 de 01/12/2011, foi um grande passo em busca de maior equidade do Sistema Único de Saúde (SUS), com o objetivo de promover saúde integral da população LGBT, eliminando discriminação e preconceito institucional e reduzindo desigualdades. Contudo, segundo Morais Neto; Tagnin; Araújo; Sousa; Barra; Hercowitz (2020), essa população tem menor acesso ao sistema de saúde, o que, em grande parte, deve-se ao atendimento não humanizado, discriminatório e resistente às questões de diversidade sexual por parte de profissionais da saúde, que sem nenhuma experiência com essas pessoas e sem entender nada sobre a questão da orientação sexual e da identidade de gênero, perpetuam o preconceito e a discriminação, e isso afasta a população LGBTI+ dos serviços públicos de saúde. 


\section{Revista \\ Debates Insubmissos}

O afastamento da população LGBTI+ dos serviços de saúde interfere na qualidade de vida dessas pessoas e por consequência adoecimentos também invisibilizados. Para Luiz (2011) o sofrimento mental entre a população LGBTI+ tem sido cada vez mais recorrente e apontado como fator de risco para muitos adoecimentos. Segundo a autora esse sofrimento é causado, na maior parte das vezes, pelo preconceito, discriminação, às várias formas de opressão, aos estigmas e à violência que estão entrelaçadas à vida dessa população. Tais questões causam um impacto enorme na saúde mental que é, mesmo invisibilizada, uma questão de saúde pública.

É imprescindível mencionar também que problemas da saúde mental pré-existentes por parte dessa população acentua sua vulnerabilidade e os impactos psicológicos durante o período de pandemia. De acordo com dados do \#VoteLGBT (2020), aproximadamente mais de $30 \%$ de pessoas LGBT's já foram diagnosticadas com algum transtorno mental (depressivos, ansiosos, de estresse pós-traumático); abuso de substâncias; comportamentos autolesivos e suicídio e durante a pandemia houve um aumento de $42,72 \%$ de problemas ligados à saúde mental e esse aspecto tem sido um dos maiores impactos para a população LGBTI+ nesse cenário.

Os impactos da pandemia estão chegando com muita força na população LGBTI+, não só no campo da saúde mental, mas no campo do desemprego e da fome. No Brasil, de acordo com Pimentel (2020), O isolamento social pode afetar também as pessoas transexuais e travestis que dependem da atividade sexual como renda. É importante lembrar também que grande parte da população LGBTI+ adquire sua renda por meio de trabalhos informais e o desemprego durante a pandemia cresceu consideravelmente entre essa população, cerca de $22 \%$, sendo que a média nacional é de $12 \%$ segundo dados do Instituto Brasileiro de Geografia e Estatística (IBGE) apresentados pela referida autora e pela pesquisa do \#VoteLGBT (2020).

A crise econômica em meio a uma pandemia, aliada a desigualdades sociais agravou ainda mais a fome, o desemprego e a precarização da vida de pessoas LGBTI+. O desemprego pode chegar a $40 \%$ e os movimentos sociais vem tentando construir formas de assistência à comunidade LGBTI+, onde o Estado brasileiro silencia e cega. Como exemplo, existem campanhas de arrecadação de roupas e alimentos para essas populações que tiveram suas vulnerabilidades agravadas pela pandemia (LEMOS; SÁ; CAVALLEIRE; RODRIGUES, 2021). 


\section{Debates Insubmissos}

Revista

A Associação Nacional de Travestis e Transexuais (ANTRA, 2020), em uma iniciativa nacional, divulgou uma cartilha especial para travestis e transexuais trabalhadoras sexuais com informações sobre a COVID-19. De acordo com a cartilha $90 \%$ da população trans se utiliza da prostituição como fonte de renda e com o isolamento social a subsistência destas profissionais é ameaçada. A cartilha traz dicas de autocuidado e estratégias de pensar um trabalho mais seguro. Nessa direção outras iniciativas, segundo Barreto (2020), foram construídas por parte de associações de moradores e ONGs (Organização Não Governamental) como promoção de direitos humanos: a criação de banco de dados de casas de acolhimento para pessoas LGBTI+; divulgação de orientações para casos de violência doméstica, monitoramento de casos de violência transfóbica, e avanço de demandas da comunidade perante órgãos públicos.

Outra questão é a dificuldade de acesso a hormonioterapia e realização de cirurgia por parte de pessoas transexuais que ficaram quase inviabilizadas durante esse período em função das restrições de funcionamento de serviços ambulatoriais desta natureza. Segundo Silva (2021) o número de atendimentos no processo de transição de gênero no SUS caiu drasticamente, as cirurgias de redesignação sexual diminuíram em $70 \%$ e a terapia hormonal em $6,5 \%$ em comparação com o ano anterior. Entretanto, a autora salienta que a saúde integral e a hormonioterapia não dizem respeito apenas a consultas e medicamentos, sendo assim, destaca também a necessidade do acolhimento e da renovação de vínculos como fatores protetivos essenciais.

O Estado peca na proteção à população LGBTI+, por exemplo, citando alguns aspectos: existe uma omissão legislativa no quesito de criminalização à LGBTIfobia, bem como deficiências quanto à criação de políticas públicas inclusivas. Essas questões que envolvem garantias de direito à vida e a saúde pioram significativamente com a pandemia de COVID-19, pois expõem ainda mais essa população à marginalização, o que corrobora com o desemprego, a fome, a dificuldade no acesso à saúde física e mental, sobretudo, direito à humanidade e à vida (GHETTI; BAHDUR, 2020).

O Ministério da Mulher, Família e dos Direitos Humanos (2020) lançou uma cartilha com orientações para a população LGBTI+ a respeito da prevenção do coronavírus. Entretanto, 
tal cartilha se dirige aos profissionais do sexo, portadores de HIV e usuário de drogas, o que, segundo Ghetti e Bahdur (2020), gerou diversas críticas pela população. A cartilha orienta ainda, conversar com os amigos para melhorar a saúde mental, procurar ONGs que estão fazendo campanhas solidárias, melhorar o currículo com educação à distância e ter fé por meios de cultos ecumênicos, como forma de prevenção ao coronavírus. Essa cartilha retira a obrigação estatal de promover políticas públicas de saúde e assistência para a população LGBTI+, escancarando ainda mais a desimportância que é dada às minorias políticas.

Lamentavelmente, a atualidade brasileira é marcada por uma crise sanitária grave devido à pandemia de COVID-19, mas também retém as marcas de uma crise política, social, econômica e ética, onde algumas das poucas conquistas da população LGBTI+, como direitos à saúde e assistência, vem sendo ameaçadas e descontruídas pela onda de conservadorismo radical, imperativos fundamentalistas religiosos e recrudescimento de pautas discriminatórias. Segundo Granados-Cosme e Delgado-Sánchez (2008) contextos assim, contribuem para o aumento de transtornos de ansiedade, depressão e risco de suicídio, fatores comuns entre a população LGBTI+.

“A pandemia de Coronavírus (COVID-19) "descortinou" vulnerabilidades comuns à população LGBTQIA+, tais como trabalho e renda, saúde mental, direito à vida e violação às suas mais diversas formas de existências" (SILVA, 2020, p. 347). Ainda em 27 de março de 2020 o painel de especialistas da Organização das Nações Unidas (ONU, 2020) emitiu uma carta aberta sobre os principais impactos do COVID-19 nas comunidades LGBT em todo o mundo, alertando que o cruzamento entre a pandemia e a LGBTfobia, estigmas e discriminação exacerbaria as violências sofridas pela comunidade LGBTI.

No atual momento do Brasil a falta da proteção do Estado, que é aumentada pelo negacionismo que assola o país em relação à pandemia, apresenta uma oposição às práticas de prevenção e cuidado com a saúde da população em geral, mas principalmente com as marginalizadas. Nega-se a realidade e nega-se as vidas LGBTI+. Nega-se direitos humanos saúde, assistência social, renda, moradia, afeto - e tudo que diz respeito à população LGBTI+. 


\section{ALGUMAS CONSIDERAÇÕES}

É inegável o impacto das medidas de isolamento/distanciamento social em toda população brasileira. Assim como mostram Bezerra, Saintrain, Braga, Santos, Lima, Brito e Pontes (2020) o medo de se infectar, a alteração na rotina diária, distanciamento das pessoas, o luto e a preocupação com a economia têm afetado a saúde mental das pessoas no Brasil. Para além dessas questões, ainda existem o colapso dos serviços públicos de saúde, bem como a forma que o país vem enfrentando e gerindo a pandemia. No entanto, as problemáticas em torno dessa vivência em pessoas LGBTI+ nos permitem pensar que as fragilidades já vividas, por essa população, podem ser intensificadas a partir de medidas como as que vem sendo adotadas na pandemia, como o distanciamento/isolamento social.

Como discutido, os achados de alguns estudos já mostram os impactos deste momento na população LGBTI+, os quais escancaram uma grande marginalização e invisibilidade dessa população. Tais resultados revelam que pensar em ficar em casa, em isolamento com familiares que não aceitam a orientação sexual ou identidade de gênero, pode ser mais perigoso em razão dos índices de violência intrafamiliar. Outros estudos nos dizem que é mais difícil ter acesso aos serviços de saúde, tanto pela discriminação e preconceito, quanto porque inexistem políticas de saúde específicas para a população LGBTI+, sobretudo, para pessoas trans e transexuais. Acentua-se também que o desemprego e a fome que assolam o país têm um percentual ainda maior entre a comunidade LGBTI+, assim como, refletem que habitar as ruas, lugar de ocupação e luta, é perigo não somente pelo medo de ser assassinado pela LGBTIfobia, mas também por um vírus mortal que acaba por denunciar a fragilidade na garantia por direitos básicos de vida e humanidade.

O atual cenário político e governamental brasileiro, no que tange às questões voltadas para a população LGBTI+, está conduzido (ou projetado) para negar o reconhecimento das formas plurais de existência e os direitos de lésbicas, gays, bissexuais, travestis, mulheres transexuais, homens transexuais e pessoas intersexuais, promovendo uma maior precariedade de direitos e anulação das ações de políticas públicas. Logo, faz com que essas pessoas estejam ainda mais vulneráveis a serem exploradas e violentadas com mais contundência do que as 


\section{Revista \\ Debates Insubmissos}

outras. E estar exposto a violências e preconceitos em meio a uma pandemia e com ausência do Estado levam essas vidas à precariedade.

Diante do que foi pensado e exposto é importante refletir o quanto vivenciamos atmosferas marcadas por preconceitos e discriminação, as quais desvelam-se como estruturais, graves e presentes ao longo da história, relacionadas à população LGBTI+. No Brasil, os dados já sinalizados no presente texto, desvelam a assustadora violência contra pessoas LGBTI+, assim como, a desarticulação de direitos fundamentais e garantidos, outrora conquistados, e agora sendo retirados. É desanimador ver a existência dessa população ameaçada cotidianamente no cenário brasileiro, quer seja pela falta de políticas públicas, pela invisibilidade dessas vidas, pelo desemprego, pela fome, ou pelos altos índices de mortes impetrados à comunidade LGBTI+.

É importante refletir também que ao negligenciar e negar políticas públicas específicas para a população LGBTI+, negligencia-se e nega-se também a existência de uma parcela dos cidadãos brasileiros. Discutir e elaborar políticas públicas especificamente voltadas para a população LGBTI+ e continuar com o grande debate sobre a despatologização da homossexualidade, criminalização da LGBTIfobia, saúde mental LGBTI+, dentre outras pautas importantes, podem ser ferramentas para se construir caminhos de cuidado e garantia de vida.

Apesar da cegueira estatal e de alguns prestadores de serviços em relação a população LGBTI+ durante a pandemia, nota-se com louvor a iniciativa da sociedade civil que vem se organizando e se mobilizando em suas comunidades, promovendo a construção e o fortalecimento de redes de cuidado, afeto e política. Com esses movimentos das associações e de ONG's mencionados anteriormente é possível sinalizar também a importância de fortalecer os canais participativos institucionais e estruturar lutas que reivindiquem a organização e efetivação de políticas públicas que levem em consideração demandas específicas da comunidade LGBTI+ no contexto nacional. 


\section{REFERÊNCIAS}

\section{ASSOCIAÇÃO NACIONAL DE TRAVESTIS E TRANSEXUAIS (ANTRA). Dicas para} travestis e mulheres trans profissionais do sexo em tempos de Covid-19. Porto Alegre: 2020. Disponível em: https://antrabrasil.files.wordpress.com/2020/04/dica-profissionais-dosexo-covid19-antra.pdf Acesso em: 09 ago. 2021.

BARRETO, Beatriz Santos. Subcidadania LGBTQ e proteção social na pandemia de Covid19. Revista do Nesef, Paraná, v. 9, n. 2, p. 32-50, dez. 2020.

BEZERRA, Carina Bandeira; SAINTRAIN, Maria Vieira de Lima; BRAGA, Débora Rosana Alves; SANTOS, Flaviano da Silva; LIMA, Ana Ofélia Portela; BRITO, Edla Helena Salles de; PONTES, Camila de Brito. Impacto psicossocial do isolamento durante pandemia de covid-19 na população brasileira: análise transversal preliminar. Saúde e Sociedade, [S.L.], v. 29, n. 4, p. 1-10, 2020. FapUNIFESP (SciELO). http://dx.doi.org/10.1590/s0104$\underline{12902020200412 .}$.

BRASIL. Congresso. Senado. Estabelece A Organização Básica dos Órgãos da Presidência da República e dos Ministérios. Brasília, 18 jun. 2019.

BRASIL. MINISTÉRIO DA SAÚDE. Política Nacional de Saúde Integral de Lésbicas, Gays, Bissexuais, Travestis e Transexuais. Brasília: Secretaria de Gestão Estratégica e Participativa. Departamento de Apoio À Gestão Participativa, 2013.

BRASIL. MINISTÉRIO DA MULHER, FAMÍLIA E DOS DIREITOS HUMANOS. Já sabe o que fazer para se proteger do novo coronavírus? Brasília: 2020. Disponível em https://www.gov.br/mdh/pt-br/assuntos/noticias/2020-2/abril/Corona_banner_LGBT.pdf Acesso em: 09 ago. 2021.

BROOKS, Samantha K; WEBSTER, Rebecca K; SMITH, Louise e; WOODLAND, Lisa; WESSELY, Simon; GREENBERG, Neil; RUBIN, Gideon James. The psychological impact of quarantine and how to reduce it: rapid review of the evidence. The Lancet, [S.L.], v. 395, n. 10227, p. 912-920, mar. 2020. Elsevier BV. http://dx.doi.org/10.1016/s01406736(20)30460-8.

BULGARELLI, Lucas; FONTGALAND, Arthur; MARTINS, Flávia Bozza; FERRARI, Marilia; BIANCONI, Giulliana; SILVA, Vitória Régia da. Violência contra LGBTs+ nos contextos eleitoral e pós-eleitoral. Rio de Janeiro: Gênero e Número, 2019.

BUTLER, Judith. Problemas de gênero: feminismo e subversão da identidade. 8. ed. Rio de Janeiro: Civilização Brasileira, 2015. 
CABRAL, Jacqueline Ribeiro. Imorais e subversivos: censura a LGBTs durante a ditadura militar no Brasil. Periódicus, Salvador, v. 4, n. 1, p. 127-150, abr. 2016.

DEYOUNG, Mariah; EASTBURG, Mark; EDWARDS, Evonne; HALSTEAD, Scott; MANCUSO, Amy; ROLLINGS, Heide; VANDENTOORN, Amy. Preparing Michigan for the Behavioral Health Impact of COVID-19. Pine Rest Christian Mental Health Services, Michigan, p. 1-28, jun. 2020.

FACCHINI, Regina. Entre compassos e descompassos: um olhar para o "campo" e para a "arena" do movimento LGBT brasileiro. Revista Bagoas, Natal, v. 4, n. 3, p. 131-158, jun. 2009.

FIOCRUZ. Cartilha Saúde Mental e Atenção Psicossocial - Informações Gerais. Rio de Janeiro: Ministério da Saúde, 2020.

FOUCAULT, Michel. História da sexualidade I: A vontade de saber. 13. ed. Rio de Janeiro: Edições Graal, 1988.

FUNDAÇÃO INSTITUTO DE PESQUISAS ECONÔMICAS (FIPE). Pesquisa censitária e caracterização socioeconômica da população em situação de rua e do relatório temático de identificação das necessidades dessa população na cidade de São Paulo. São Paulo: 2015. Disponível em: https://www.prefeitura.sp.gov.br/cidade/secretarias/upload/00publicacao_de_editais/0005.pdf. Acesso em: 09 ago. 2021.

GHETTI, Beatriz Pristilo; BAHDUR, Daniela Hruschka. A dificuldade do acesso à saúde pelo grupo LGBTI no brasil durante a pandemia: uma análise à luz da teoria da eficácia horizontal dos direitos humanos. Revista da Seção Judiciária do Rio de Janeiro, [S.L.], v. 24, n. 49, p. 136, 29 out. 2020. Centro Cultural Justica Federal. http://dx.doi.org/10.30749/2177-8337.v24n49p136-156

GRANADOS-COSME, José Arturo; DELGADO-SÁNCHEZ, Guadalupe. Identidad y riesgos para la salud mental de jóvenes gays en México: recreando la experiencia homosexual. Cadernos de Saúde Pública, [S.L.], v. 24, n. 5, p. 1042-1050, maio 2008. FapUNIFESP (SciELO). http://dx.doi.org/10.1590/s0102-311x2008000500011.

LEMOS, Andrey; SÁ, Jean Falcão e; CAVALLEIRE, Silvinha; RODRIGUES, Theodoro. Pandemia, LGBTfobia e os impactos das negligências do Estado para esta população. 2021. Disponível em: http://conselho.saude.gov.br/ultimas-noticias-cns/1640artigo-pandemia-lgbtfobia-e-os-impactos-das-negligencias-do-estado-para-esta-populacao. Acesso em: 26 maio 2021. 
LUIZ, Carmen Lucia. Saúde para pessoas LGBT. In: Conselho Regional De Psicologia SP (org.). Psicologia e Diversidade Sexual: cadernos temáticos CRP SP. São Paulo. 2011. p. 2532.

MENDES, Wallace Góes; SILVA, Cosme Marcelo Furtado Passos da. Homicídios da População de Lésbicas, Gays, Bissexuais, Travestis, Transexuais ou Transgêneros (LGBT) no Brasil: uma análise espacial. Ciência \& Saúde Coletiva, [S.L.], v. 25, n. 5, p. 1709-1722, maio 2020. FapUNIFESP (SciELO). http://dx.doi.org/10.1590/1413-81232020255.33672019. MORAIS NETO, Antônio Carlos de; TAGNIN, Luisa Hercowitz; ARAÚJO, Alisson Costa de; SOUSA, Maria Isabele Oliveira; BARRA, Brígida Gabriele Albuquerque; HERCOWITZ, Andrea. Ensino em Saúde LGBT na Pandemia da Covid-19: Oportunidades e Vulnerabilidades. Revista Brasileira de Educação Médica, [s. l], v. 44, n. 1, p. 1-7, set. 2020.

\section{ORGANIZAÇÃO DAS NAÇÕES UNIDAS (ONU). Carta aberta no COVID-19 à} comunidade LGBT. 2020. Disponível em:

Https://www.ohchr.org/EN/Issues/SexualOrientationGender/Pages/COVID19LGBTInclusive Response.aspx. Acesso em: 09 ago. 2021.

PIMENTEL, Thais. Pesquisa da UFMG e Unicamp aponta que população LGBT está mais vulnerável ao desemprego e à depressão por causa da pandemia. 2020. Disponível em: https://g1.globo.com/mg/minas-gerais/noticia/2020/05/17/pesquisa-da-ufmg-e-unicampaponta-que-populacao-lgbt-esta-mais-vulneravel-ao-desemprego-e-a-depressao-por-causa-dapandemia.ghtml. Acesso em: 03 maio 2021.

POLITIZE! Vulnerabilidade Social: o que significa esse conceito? 2020. Disponível em: https://www.politize.com.br/vulnerabilidade-social/. Acesso em: 09 ago. 2021.

RAMÍREZ-ORTIZ, Jairo; CASTRO-QUINTERO, Diego; LERMA-CÓRDOBA, Carmen; YELA-CEBALLOS, Francisco; ESCOBAR-CÓRDOBA, Franklin. Consecuencias de la pandemia covid 19 en la salud mental asociadas al aislamiento social. Scielo Preprints, [S.L.], p. 1-21, 3 maio 2020. FapUNIFESP (SciELO).

http://dx.doi.org/10.1590/scielopreprints.303.

REIS, Toni. Avanços e Desafios para os Direitos Humanos da Comunidade LGBT no Brasil. In: Congresso Brasileiro de Direito de Família, 8., 2012, Belo Horizonte. Família: entre o público e o privado. Porto Alegre: Instituto Brasileiro de Direito de Família, 2012. p. 370384.

SILVA, Fabiano Saft. O "descortinamento" das vulnerabilidades da população LGBTQIA+ diante a pandemia de coronavírus. Psicologia e Saúde em Debate, [S.L.], v. 6, n. 2, p. 346- 
355, 22 dez. 2020. Psicologia e Saúde em Debate. http://dx.doi.org/10.22289/2446922x.v6n2a23.

SILVA, Vitória Régia da. Cirurgias do processo transexualizador caem $70 \%$ em 2020 e denúncias de "esvaziamento" na saúde revelam risco para população trans. 2021. Disponível em: http://www.generonumero.media/saude-trans/. Acesso em: 26 maio 2021. TRZAN-Á VILA, Alexandre. Identidade de gênero: performatividade, ser-aí e subversões. Rio de Janeiro: Ifen, 2019.

VECCHIATTI, Paulo Roberto Iotti. Manual da homoafetividade: da possibilidade jurídica do casamento civil, da união estável e da adoção por casais homoafetivos. São Paulo: Método, 2012.

\#VOTELGBT. Diagnóstico LGBT+ na Pandemia: desafios da comunidade LGBT+ no contexto de isolamento social em enfrentamento à pandemia de coronavírus. Desafios da comunidade LGBT+ no contexto de isolamento social em enfrentamento à pandemia de Coronavírus. 2020. Colaboração BOX1824. Disponível em:

https://static1.squarespace.com/static/5b310b91af2096e 89a5bc1f5/t/5ef78351fb8ae15cc0e0b5 a3/1593279420604/\%5Bvote+lgbt+\%2B+box1824\%5D+diagno\%CC\%81stico+LGBT\%2B+ na+pandemia_completo.pdf. Acesso em: 03 maio 2021.

WORLD HEALTH ORGANIZATION (ORG.). Mental health and psychosocial considerations during the COVID-19 outbreak. Genebra: World Health Organization, 2020 .

Submetido: $28 / 05 / 2021$

Aprovado: 26/08/2021 